\title{
LA DECRETAL DEL PAPA HONORIO I A LOS OBISPOS HISPANOS (638): UNA HIPÓTESIS SOBRE SU ORIGEN*
}

\section{POPE HONORIUS I'S DECRETAL TO THE HISPANIC BISHOPS (638): A HYPOTHESIS ABOUT ITS ORIGIN}

\author{
Juan Antonio JimÉnez Sánchez \\ Universidad de Barcelona \\ jjimenez@ub.edu \\ ORCID: 0000-0002-7382-1278
}

DOI: $10.1387 /$ veleia. 17974

\begin{abstract}
Resumen: En el presente trabajo estudiamos la decretal enviada por el papa Honorio I a los obispos reunidos en el Concilio VI de Toledo (638). En ella, el pontífice reprochaba a los hispanos su permisividad con los enemigos de la fe, sobre todo con los judíos bautizados que habían vuelto a sus costumbres judaizantes. No conservamos la misiva, pero resulta posible reconstruirla a partir de la respuesta que Braulio de Zaragoza escribió en nombre del resto de prelados. Esto nos permite centrarnos en las causas que pudieron llevar al papa a redactar su decretal: esta se originó por los rumores difundidos por unos maledicentes. La cuestión estriba en dilucidar la identidad de estos individuos. En nuestra opinión, serían rebeldes exiliados a otros países; desde allí, para ganarse el favor papal, habrían formulado estas acusaciones contra los obispos y, de manera implícita, contra el rey godo.
\end{abstract}

Palabras clave: Braulio de Zaragoza, epístola, concilio, judíos, usurpadores, exiliados.

Abstract: This paper analyses the decretal sent by Pope Honorius I to the bishops who took part at the Sixth Council of Toledo (held in 638). In this letter, the pontiff rebuked the Hispanics for being so permissive with the enemies of the faith, especially with the baptized Jews who had returned to their Judaizing customs. Despite the fact that this text is not preserved, the reply of Braulio of Zaragoza to the pontiff, written on behalf of the prelates at the aforementioned Council, has made it feasible to reconstruct its contents. Furthermore, Braulio of Zaragoza's reply also allows us to focus on the reasons which might have led the Pope to compose his decretal, namely rumours spread by some unidentified slanderers. In this sense, the aim of this paper is to elucidate the identity of these individuals. As far as we are concerned, they would be rebels exiled to other countries from which, with the intention

\footnotetext{
* Este estudio se enmarca en los proyectos de investigación HAR2016-74981-P del Ministerio de Economía y Competitividad, cuyos investigadores principales son los profesores Josep Vilella y Juan Antonio
}

Jiménez, y del GRAT, Grup de Recerca 2014SGR-362, de la Direcció General de Recerca de la Generalitat de Catalunya, dirigido por el profesor Josep Vilella. 
of gaining papal favour, they would have made these accusations against the bishops and, implicitly, against the Gothic king.

Keywords: Braulio of Zaragoza, epistle, council, Jews, usurpers, exiled.

Recibido: 4/7/2017

Informado: 16/11/2017

Definitivo: 19/1/2018

El día 9 de enero del año 638 se reunió, convocado por Chintila, el Concilio VI de Toledo en la iglesia de Santa Leocadia de esta ciudad. En él participaron cuarenta y ocho obispos, tres de ellos procedentes de la Narbonense, además de tres presbíteros y dos diáconos — vicarios de sus respectivos obispos-, con lo que, a diferencia del anterior sínodo toledano, este fue considerado como una reunión de prelados hispanos y galos. Mientras se hallaban aún congregados, se presentó el diácono Turnino, quien era portador de una epístola del papa Honorio I dirigida a los obispos hispanos $^{1}$. Esta carta, en la que el sucesor de Pedro dedicaba a los prelados duros reproches por su tibieza en la lucha contra los enemigos de la fe, por desgracia no se nos ha conservado ${ }^{2}$, pero resulta posible reconstruirla a partir de la respuesta que, a petición de aquellos, se encargó de redactar Braulio de Zaragoza ${ }^{3}$, quien también asistía a este concilio ${ }^{4}$.

$\mathrm{Al}$ inicio de la epístola (Braul. Caes., Ep., 21 [p. 108-114]) , Braulio alababa prudentemente la dedicación de Honorio I en su cometido de vigilar con celo y de expurgar la casa de Dios de prevaricadores y apóstatas execrables. Sin embargo, añadía, el rey Chintila había llegado a la misma conclusión por inspiración divina y sagradas meditaciones. Todo esto no podía ser otra cosa, para el obispo de Zaragoza, que una prueba más de la voluntad providencial de Dios omnipotente, quien simultáneamente había despertado el mismo deseo en el corazón del monarca y en el del papa de Roma, a pesar de la gran distancia que los separaba a ambos. Y por esta razón, los obispos daban gracias al Señor, pues lo más importante para el ser humano era obedecer los preceptos divinos.

1 Se trata de la primera decretal llegada a Hispania desde la muerte del papa Gregorio Magno en el 604 (Thompson 20075, 219).

2 Acerca de esta decretal desaparecida, véase: Jaffé 1885, 226, n. ${ }^{\circ} 2038$; Conte 1971, 417, n. ${ }^{\circ}$ 63. Fidel Fita considera que debió haber otra carta de Honorio I dirigida a Chintila, así como diversas misivas enviadas al primado de Toledo y a otros personajes (Fita 1871, 404).

${ }^{3}$ La carta está escrita en nombre de todos los obispos hispanos (buniuersi episcopi per Spaniam constituti), y no contiene ninguna referencia directa a Braulio. Con todo, y a partir sobre todo de una noticia recogida en la Chronica Muzarabica anni 754 (Chron. Muzar. a. 754, 17 [p. 186]: huic sancto sinodo inter ceteros Braulio Cesaragustanus episcopus claruit, cuius eloquentiam Roma urbium mater et domina postmodum per epistolare alloquium satis mirauit), la tradición ha atribuido secularmente esta epístola al obispo de Zaragoza, una atribución confirmada por la crítica filológica (Vega 1942, 95). El sínodo mencionado aquí por la crónica corresponde al IV de Toledo, celebrado en el año 633 durante el reinado de Sisenando. De ahí que el anónimo cronista utilice el adverbio postmodum para enfatizar que, pese a que Braulio ya destacó en el Concilio IV de Toledo, su elocuencia sería admirada por Roma "posteriormente» a esta reunión episcopal (Lynch-Galindo 1950, 149-150; López Pereira 2009, 187, n. 24). Acerca de la fortuna literaria de esta epístola de Braulio, véase Miguel 2010, 293-295.

${ }^{4}$ La Chronica Muzarabica anni 754 (Chron. Muzar. a. 754, 18 [p. 188]: huic sinodo Braulio Cesaragustanus episcopus pre ceteris illustris excellit atque piam doctrinam Xpianis mentibus decenter infundit, cuius et opuscula nunc usque eclesia relegit) recuerda el importante papel desempeñado por Braulio de Zaragoza en el Concilio VI de Toledo, aunque el cronista confunde de manera errónea este sínodo con el V de Toledo (Vega 1942, 96).

${ }^{5}$ La epístola 21 de Braulio ha sido muy estudiada, especialmente en relación con la situación de los judíos en el Reino Visigodo. Entre los principales estudios, y sin ánimos de ser exhaustivos, destacamos los siguientes: Fita 1870-1871; Vega 1942, 95-109; Conte 1971, 417418, n. ${ }^{\circ}$ 64; Orlandis 1987, 149-151; García Moreno 1993, 119-120 y 151-152; Riesco 1993; González Salinero 2000, 43-51; Ferreiro 2009; Cabrera 2014, 103105; Rodamilans 2014, 449-450. 
Después de este exordio, Braulio pasaba a rebatir las acusaciones de Honorio $\mathrm{I}^{6}$. Rechazaba que los obispos se hubieran mostrado indolentes y que se hubieran olvidado de su deber; los predicadores no habían actuado con despreocupación, sino más bien con indulgencia, tal como recomendaba el Apóstol, quien pedía que se corrigiera con mansedumbre (2 Tim., 2, 25). Los prelados preferían utilizar la dulzura cristiana a rígidos castigos, y así la victoria resultaba más grande si se la difería. De este modo, Braulio concluía que nada de lo que el papa les había reprochado les concernía en absoluto (et liceat nos horum, que in obiurgionem nostri uestra Sanctitas indebite protulit, pro hac dumtaxat actione nicil omnino respectet [p. 110]). Es más, el zaragozano incluso se atrevió a corregir al pontífice, pues este había dicho de los hispanos que eran como "perros mudos incapaces de ladrar» (canes muti non ualentes latrare [p. 110]) ${ }^{7}$, atribuyendo erróneamente a Ezequiel esta cita ${ }^{8}$, cuando en realidad era de Isaías (Is., 56, 10), como con acierto señaló Braulio. Se trataba, en opinión del prelado, de una reprensión inmerecida, ya que los obispos habían hecho públicos los castigos de los transgresores en los lugares adecuados y en ningún momento habían callado su predicación (Lynch-Galindo 1950, 153156; Riesco 1993, 597).

A continuación, y para probar sus palabras, Braulio comunicaba al papa que junto con la carta le enviaba las actas de los concilios pasados junto con las del presente. Aunque no especificó a qué sínodos exactamente estaba haciendo referencia, podemos conjeturar que con toda probabilidad se trataría de los celebrados a partir de la conversión de la monarquía al catolicismo, es decir, los concilios toledanos III (589) y IV (633) —el V (636) no contaba con ningún canon relativo a este tema-, así como el que se estaba realizando en aquel momento, el VI (638)9. Por lo que respecta a los enemigos de la fe, en el primero de ellos, celebrado bajo Recaredo, se anatemizó a cualquier seguidor del arrianismo o a cualquiera que adoptara una doctrina fuera de la Iglesia católica

6 La contundencia en la respuesta de Braulio no debe llevarnos a pensar en modo alguno que los obispos hispanos cuestionasen la primacía del papa. Como acertadamente ha señalado Alberto Ferreiro: «the See of Rome was seen as possessing the universal jurisdiction to intervene directly into Iberian ecclesial affairs. There is nothing herein to suggest that this was in any way novel or even in any way as an intrusion by the papacy. In fact, there are abundant examples before and during Braulio's time of papal involvement in Iberian ecclesial affairs» (Ferreiro 2009, 92). Acerca del respeto de Braulio y el resto de obispos hispanos por la primacía de Roma, véase: Fita 1871, 49-60; Vega 1942, 106109; Lynch-Galindo 1950, 65-66, 117-120 y 169171; Conte 1971, 418; Aznar 1986, 100-103; Orlandis 1987, 150; Saitta 1995, 61; Ferreiro 2009, 86-88. En un sentido contrario, y defendiendo la autonomía de la Iglesia visigoda frente a la sede apostólica de Roma (por la que se reconocería su prestigio, pero no su primacía jurisdiccional): Lacarra 1960, 363-365; García Moreno 2011, 535-536.

7 Esta cita veterotestamentaria hacía referencia a los perros pastores que restaban mudos ante un determinado peligro que amenazaba al rebaño que habían de cuidar. Como metáfora del predicador indolente gozó de un gran éxito, y así fue recordada, antes de Honorio I, por Gregorio Magno (Greg. Magn., Moral. in Iob, XX, 6, 15 [vol. 143A, p. 1014]) e Isidoro de Sevilla (Isid. Hisp., Sent., III, 35, 2 [p. 276]), y posteriormente por otros pontífices romanos. Al respecto, véase Kendall 2006. Por su parte, Alberto Ferreiro realiza un muy interesante análisis del simbolismo bíblico-teológico que Braulio utilizó en su respuesta: además de la cita de Isaías referida a los "perros mudos incapaces de ladrar» (Ferreiro 2009, 90), menciona también la túnica sin costuras del Señor (Ferreiro 2009, 88-89), la limpieza del Templo por parte de Cristo (Ferreiro 2009, 89), Elías y los profetas de Baal (Ferreiro 2009, 89-90) y la alegoría de Escila y Caribdis (Ferreiro 2009, 92-93).

8 Resulta muy probable que Honorio I no hubiera tomado esta cita directamente de las Sagradas Escrituras, sino de la Regula pastoralis de Gregorio Magno. Un pasaje de esta obra (Greg. Magn., Reg. past., II, 4 [vol. 381, p. 188]) recoge la cita de Isaías y justo a continuación expone otra de Ezequiel (Ez., 13, 5), lo que pudo provocar la confusión de Honorio I.

9 Fidel Fita estima que se trataría tan solo de los cánones del Concilio IV de Toledo, junto con los del que se estaba realizando en ese momento (Fita 1871, 192200 y 412-414). 
(Conc. Tol. III, Goth. prof. fidei [p. 75-99]); se prohibió que los judíos pudieran casarse con cristianas o tenerlas por concubinas, así como que pudieran tener esclavos cristianos; además, no podrían desempeñar cargos públicos, a fin de que no dispusieran de la oportunidad de imponer penas a los cristianos (Conc. Tol. III, 14 [p. 120-121]); igualmente, se decretó que los sacerdotes y los jueces deberían buscar en sus respectivos territorios signos de idolatría y extirparlos, castigando al mismo tiempo a los idólatras; si no lo hacían así, serían excomulgados, al igual que los señores que no terminaran con las muestras de paganismo que observaran en sus posesiones (Conc. Tol. III, 16 [p. 122-123]).

En el Concilio IV de Toledo, reunido bajo Sisenando, al igual que en los siguientes sínodos que veremos, los únicos enemigos de la fe que despertaron la preocupación de los obispos fueron los judíos. Así, se decidió que no se les podía obligar a convertirse - al contrario de lo que había sucedido en tiempos de Sisebuto-; con todo, aquellos que habían sido forzados a bautizarse durante el reinado de este monarca debían continuar siendo cristianos (Conc. Tol. IV, 57 [p. 235-236]); se prohibió que nadie apoyara a los judíos contra la fe cristiana a cambio de dádivas (Conc. Tol. IV, 58 [p. 236-237]); se decidió asimismo que aquellos hebreos bautizados que habían regresado al judaísmo debían volver al dogma cristiano (Conc. Tol. IV, 59 [p. 237-238]); que sus hijos fueran separados de sus padres y entregados a cristianos (Conc. Tol. IV, 60 [p. 238]); que los hijos de judíos bautizados, en el caso de que sus progenitores cometieran algún delito, percibieran igualmente su herencia (Conc. Tol. IV, 61 [p. 238]); que los judíos convertidos al cristianismo no tuvieran ningún tipo de trato con aquellos que aún no habían renunciado a su religión (Conc. Tol. IV, 62 [p. 239]); que los judíos no se casaran con cristianas ni las judías con cristianos; si se producía el caso, debían convertirse o separarse, y si habían tenido hijos, estos serían cristianos (Conc. Tol. IV, 63 [p. 239240]); también se decretó que los judíos convertidos, pero que después habían dado muestras de que su conversión no había sido sincera - aunque ellos sostuvieran lo contrario- no podrían actuar como testigos (Conc. Tol. IV, 64 [240]); que no desempeñaran cargos públicos (Conc. Tol. IV, 65 [p. 240-241]); y que no tuvieran esclavos cristianos; si se daba el caso, estos serían liberados (Conc. Tol. IV, 66 [p. 241-242]).

El Concilio VI de Toledo significó un nuevo giro, todavía más radical, en la política contra los hebreos, pues Chintila decidió regresar a la política de conversiones forzosas practicada por Sisebuto $^{10}$. De este modo, en el sínodo se anunció que el rey no tenía intención de dejar vivir en su reino a nadie que no fuera católico — en referencia a los judíos—, y se sancionó que, en el futuro, cualquiera que pretendiera subir al trono debería prometer que los seguidores de la ley mosaica no violarían la fe católica ni prevaricarían; quien quebrantara esta promesa sería anatema (Conc. Tol. VI, 3 [p. 304-307]; véase González Salinero 2000, 43-47).

Llegamos de este modo a un pasaje de la carta de Braulio que consideramos crucial y fundamental para comprender el motivo que impulsó al pontífice romano a escribir su decretal a los obispos

${ }^{10}$ La dureza de la política antijudía dictada en el Concilio VI de Toledo tal vez fue la respuesta del rey Chintila y de los obispos hispanos a las duras críticas recogidas en la decretal de Honorio I — por lo que no podemos saber cuál hubiera sido la postura adoptada en ese sínodo en relación con los judíos de no haber mediado la carta papal-. Véase: Lynch-Galindo 1950, 156; Orlandis 1987, 149; Saitta 1995, 59: González Salinero 2000, 47 y 50-51. En contra,
Riesco 1993, 600, quien considera la opción contraria: la dura postura de Chintila con respecto a los judíos habría sido anterior a la epístola papal, y posteriormente habría contado con el «apoyo moral» de Honorio I. De este modo, este investigador considera incluso la posibilidad de que la decretal del pontífice dirigida a los prelados hispanos hubiera tenido como objetivo invitar a los obispos a apoyar de una manera definitiva a Chintila. 
hispanos: arbritramus enim putasse falsiloquos facile aures mansuetudinis uestre opinioni patere sinistre, quum sepe soleat sine auctore falsa dictio euagare adque leuitate sui mentes instabiles penetrare [p. 110]. Gente malintencionada había hecho llegar una serie de rumores hasta Honorio I, con la esperanza de que fueran creídos por los oídos bondadosos del papa. Sin embargo, añadía Braulio a fin de no dejar al vicario de Cristo como un crédulo, los obispos hispanos estaban convencidos de que el fingimiento de la serpiente, es decir, la mentira, no había hecho mella en la piedra de Pedro, de igual modo que los obispos tampoco habían creído las historias que llegaban desde Roma, según las cuales el papa había autorizado a los judíos bautizados a volver a la superstición de su religión (González Salinero 2000, 48; Ferreiro 2009, 84-85).

Braulio exhortaba a Honorio I a proseguir con celo en su lucha contra los enemigos de Cristo, aunque eso sí, al finalizar la epístola le solicitaba que ponderase si los culpables de apostasía deberían ser castigados con penas tan duras como las que recomendaba el pontífice, pues se trataba de condenas que no encontraban paralelo ni en la tradición de los mayores ni tampoco en las Escrituras (González Salinero 2000, 50; Ferreiro 2009, 85-86) ${ }^{11}$.

Llegados a este punto, nos planteamos qué fue lo que empujó a Honorio I a escribir su decretal a los obispos hispanos. Se trata de una cuestión que, en nuestra opinión, no ha llamado suficientemente la atención de los investigadores que han estudiado la respuesta de Braulio y que, no obstante, resulta ciertamente interesante, ya que nos ayuda a arrojar una nueva luz sobre la dinámica de las relaciones internacionales en el Mediterráneo occidental durante la primera mitad del siglo vir. Por supuesto, la clave se halla en la frase que hemos señalado anteriormente: los mentirosos (falsiloqui) habían creído que los oídos del papa estarían abiertos fácilmente a opiniones desfavorables. Está claro, como ya señaló Ángel Custodio Vega en su día (Vega 1942, 98; en el mismo sentido, Ferreiro 2009, 92), que Honorio I no tenía un conocimiento exacto de la política contra los judíos que se estaba llevando a cabo en el Reino Visigodo; de ahí que los obispos reunidos en el Concilio VI de Toledo decidieran enviarle una copia del presente sínodo

11 Braulio no especifica qué penas eran las decretadas por el papa, por lo que este aspecto resta oscuro. Tan solo podemos conjeturar que debían ser especialmente severas, hasta el punto de provocar el asombro y el rechazo de los obispos hispanos. Fita 1881, 57-58, opina que se trataría de la hoguera. Desconocemos, sin embargo, cuál fue el alcance real de la política de Honorio I en relación con los judíos. Existe un consenso general entre los investigadores en que debió ser dura, aunque el único dato que tenemos al respecto proviene del epitafio del pontífice y aun esta noticia resulta muy parca: Iudaicae gentis sub te est perfidia uicta, sic unum Domini reddis ouile pium (Durliat 1998, 72). Segun Jean Durliat (1998, 74), Honorio I no tomó iniciativas propias en este terreno, sino que se limitó a aplicar la legislación promulgada por Heraclio (610-641), el primer emperador bizantino que llevó a cabo una política de bautismos forzosos entre los judíos; no olvidemos que, al fin y al cabo, el obispo de Roma era un súbdito imperial; véase Conte 1971, 42. En este sentido, para Durliat la carta del papa a los obispos hispanos habría sido un intento por su parte de que se impusieran en el Reino Visigodo las directrices orientales, algo a lo que se negaron los prelados hispanos. Por su parte, Gilbert Dagron y Vincent Déroche $(2010,36-37)$ sostienen que afirmar que Honorio I actuaba de acuerdo con Heraclio y que presionaba para que se ejecutaran sus medidas en los territorios que dependían de él es ir demasiado lejos: «les dates interdisent de penser à un vaste plan conçu et coordonné par l'empereur byzantin ou par le pape». En todo caso, Heraclio fue el primer emperador en forzar las conversiones de judíos seguramente ya en el 632, pues necesitaba imponer la unidad religiosa en la ecúmene cristiana como un medio de lograr la cohesión social y política del Imperio; además, su política antijudía estuvo muy condicionada por la ocupación de Siria y Palestina por parte de los persas, y especialmente por la colaboración activa de la comunidad judía en la toma de Jerusalén en el 614, episodio muy traumático para los cristianos; al respecto, véase: Sharf 1995, 56-58; Kaegi 2003, 216-217; Bonfil 2012, 78-87; Magdalino 2013. Que el papa Honorio I intentara aplicar estas mismas medidas en los territorios controlados por él resulta, por tanto, una posibilidad absolutamente lógica y verosímil. 
junto con las de los anteriores ${ }^{12}$. Unos falsiloqui debieron comunicarle al pontífice que desde el año 633, con las medidas tomadas en el Concilio IV de Toledo, se había producido una relajación en el tema de los hebreos, reflejada especialmente en el abandono de los bautismos forzosos llevados a cabo desde los tiempos de Sisebuto. Esto habría provocado el enfado del sucesor de Pedro y su airada carta a los obispos hispanos. Ahora bien, la cuestión estriba en dilucidar quiénes eran estos falsiloqui.

Fidel Fita asume que en el origen de la decretal de Honorio I hubo un falso rumor, pero juzga que el papa nunca hubiera dirigido sus quejas al episcopado hispano de no haber existido un documento que lo hubiera incitado a ello, en concreto el canon 57 del Concilio IV de Toledo. Fita opina que en todo este asunto no tuvo por qué haber mala fe. Supone que Chintila, en el momento de su coronación, decidió mostrar su adhesión al sucesor de Pedro enviándole un presente junto con una misiva. Este autor especula con la posibilidad de que fueran los emisarios que llevaron al pontífice el regalo y la carta del rey los que le informaron, sin ningún tipo de mala intención, acerca de lo decretado en el canon mencionado, y que de ahí resultase el enfado de Honorio I. Fita culpa además a los judíos, con un espíritu antisemita propio de su siglo, de gran parte de los males del mundo en aquellos días: recuerda su colaboración con los persas y más adelante con los musulmanes, ayudándoles en sus conquistas y traicionando a los cristianos que, según Fita, los protegían. Esto explicaría, en opinión de este autor, la alarma de Honorio I y su demanda de ayuda a los prelados hispanos (Fita 1871, 404-410 y 416-417).

Ángel Custodio Vega considera que el papa se había visto «influido por rumores o insidias de personas mal intencionadas» (Vega 1942, 97), y piensa que estos maldicientes serían los mismos que a su vez los esparcían «en sentido contrario en España contra Roma, para engendrar sospechas y celos entre ambas" (Vega 1942, 109). No obstante, y a pesar de lo sugerente de esta hipótesis, Vega no va más allá a la hora de intentar otorgar una posible identidad a estos concitadores.

Por su parte, Luis A. García Moreno juzga que en el origen de esta decretal se halla una disputa entre dos facciones clericales en la península ibérica: por un lado, un partido más moderado representado por Braulio de Zaragoza — sucesor en el liderazgo eclesiástico de Isidoro de Sevilla, el responsable de que en el Concilio IV de Toledo se acabase con la política de bautismos forzosos impuestos por Sisebuto-; por otro lado, una facción más intolerante, que contemplaría las disposiciones tomadas bajo Sisenando en el 633 como un retroceso y una concesión a los judíos (García Moreno 1993, 151). Como ya hemos visto, en el Concilio $\mathrm{V}$ de Toledo (636), celebrado bajo el liderazgo de Braulio, no se tomó ninguna medida contra los judíos, lo que, según García Moreno, «pudo considerarse como un logro de estos sectores moderados» (García Moreno 1993, 151-152). Y precisamente aquí encuentra García Moreno la razón de ser de la decretal de Honorio I: «es posible que sus oponentes políticos considerasen oportuno acudir a presiones y apoyos exteriores para imponer sus puntos de vista» (García Moreno 1993, 152). Tras haber informado al papa, este habría enviado a los obispos visigodos su durísima decretal, la cual "tiene todo el tufillo de una burda manipulación facciosa» (García Moreno 1993, 152). El hecho de que en el Concilio VI de Toledo se volviera a la política de las conversiones forzosas supondría la victoria de los radicales y evidenciaría la efec-

12 En contra, Riesco 1993, 594, quien sostiene que el papa sí estaba al corriente de la política sobre los judíos llevada a cabo por los monarcas visigodos. En el mismo sentido, Judic 2013, 102, quien además opina que Honorio estaba inquieto por la política so- bre la conversión forzosa de los judíos — tan contraria a la de su mentor Gregorio Magno- que se estaba llevando a cabo en el Reino Visigodo, lo que probablemente le llevó a escribir a los obispos hispanos. 
tividad de la misiva papal (la misma hipótesis, puesta en relación con la compleja panorámica internacional, en García Moreno 2011, 533-536).

Alberto Ferreiro expresa una opinión muy similar a la de García Moreno, puesto que afirma que seguramente ciertos clérigos anónimos —obispos y sacerdotes—, que estaban en desacuerdo con aquellos que apoyaban a Braulio - partidarios tal vez de una política algo más tibia en relación con los judíos, basada en la predicación y no en la coerción-, se habrían dirigido a Honorio I a fin de informarle de lo que estaba sucediendo en la península ibérica (Ferreiro 2009, 77, 84 y 93).

Aunque consideramos estas últimas hipótesis lógicas y perfectamente válidas, desearíamos exponer una posibilidad más. Es probable que el responsable de levantar calumnias ante Honorio I contra Chintila y los obispos hispanos no fuera un clérigo intransigente, sino algún otro individuo cuya intención fuera provocar una cierta inestabilidad política en el seno del Reino Visigodo; para ello recurriría a difundir una imagen negativa, fundamentada en la permisividad religiosa, tanto del rey como de la Iglesia hispana. En este punto, traeremos a colación, a modo de ejemplo, una interesante anécdota narrada por Gregorio de Tours. Este refiere que en su tiempo (580), el rey Leovigildo envió a un tal Agila como embajador ante el monarca franco Chilperico I. Al pasar por Tours, Agila mantuvo una discusión teológica con Gregorio, obispo de la ciudad. El embajador le pidió, ante sus continuos ataques, que no blasfemase contra su fe, dado que los godos arrianos, pese a no compartir las creencias de los católicos, no blasfemaban contra ellas. De hecho, prosiguió Agila, en el Reino Visigodo no se consideraba un crimen profesar tal o cual creencia, por lo que resultaba posible reverenciar al mismo tiempo un altar pagano y una iglesia de Dios, venerando así a ambos simultáneamente. Ante esto, Gregorio le acusó de ser un defensor de paganos y de herejes, lo que finalmente motivó el enojo y la marcha del embajador (Greg. Tur., Hist., V, 43 [p. 249-252]) ${ }^{13}$. Evidentemente, las palabras que el obispo de Tours puso en la boca de Agila constituían una falsedad, pues no hay constancia de que los arrianos fueran más tolerantes con los comportamientos paganizantes de lo que pudieron ser los católicos. Sin embargo, este discurso cumplía perfectamente su papel de presentar ante los posibles lectores una imagen desprestigiada y del todo negativa de los visigodos, mostrándolos como unos individuos en exceso permisivos en materia de religión, y, por ende, favorecedores de cultos que iban en contra del cristianismo.

Resulta muy plausible que en el caso que nos ocupa se hubiera producido una situación similar. No tenemos por qué pensar aquí en los francos como origen de la maledicencia, ya que en este momento no parece que las relaciones entre ambos reinos fueran especialmente conflictivas. La última vez que un ejército franco había intervenido en la península ibérica había sido en el año 631, cuando un grupo de nobles godos conspiró para expulsar del trono a Suintila y para ello solicitaron la ayuda de las tropas de Dagoberto de Neustria, quien accedió a auxiliarlos a cambio de una bandeja de oro, valorada en quinientas libras de peso, que a mediados del siglo v Aecio había regalado al monarca visigodo Turismundo. Gracias a dicha intervención, Suintila abdicó del trono y Sisenando pudo llegar al poder (Fredeg., Chron., IV, 73 [p. 157-158]; véase: García Moreno 1998², 155-156; Thompson 20075 , 204-205; García Moreno 2011, 523-528).

13 Acerca de este episodio, véase: McKenna 1938, 114-115 (concede crédito a las palabras de Agila respecto a la tolerancia, e incluso indiferencia, de los arrianos en materia religiosa); Saitta 1986, 77; Orlandis 1992, 71-74; Van Dam 1993, 72, n. 106 y p. 106-107; Orlan- dis 2006'2, 363-365; Ferreiro 2010, 285-286; Mathisen 2014, 175, 179 y 186 (considera que las palabras de Agila demuestran que había una convivencia real entre nicenos y arrianos, a pesar de los esfuerzos de los nicenos más rigoristas en mantener separadas ambas comunidades). 
Encontramos factible que la propagación de estos rumores en el entorno del pontífice romano proviniera de algún godo huido del Reino Visigodo a causa de un fallido intento de hacerse con el poder. Refugiado en algún reino vecino, e intentando encontrar aliados, promovería en el extranjero una imagen excesivamente laxa del monarca y de los obispos godos. Se trataba, al fin y al cabo, de una campaña de desprestigio y de propaganda negativa. Contamos con algunos textos de esta época que nos indican que el reinado de Chintila debió de resultar problemático en materia de intentos frustrados de usurpación por parte de individuos que posteriormente buscaron amparo y posibles apoyos entre los potenciales enemigos, o al menos rivales, del monarca godo.

Precisamente, un canon del Concilio VI de Toledo (Conc. Tol. VI, 12 [p. 318-319]) hacía referencia de manera explícita a aquellos sujetos que buscaban abrigo entre los enemigos del Reino, defendiendo así las virtudes de los adversarios y atrayendo detrimento a su pueblo y a su patria. Sobre estos, el sínodo decidió que fueran reducidos a la potestad del monarca, excomulgados, encerrados y sometidos a la más larga penitencia (prauarum audacia mentium saepe aut malitia cogitationum aut causa culparum refugium appetit hostium; unde quisquis sacrator causarum exstiterit tali uirtute se nitens defendere aduersariorum et patriae uel gentis suae detrimenta intulerit rerum, in potestate principis ac gentis deductus, excommunicatus et retrusus, longinquioris paenitentiae legibus subdatur). En caso de que el culpable mostrara arrepentimiento y se acogiera a la iglesia, la propia intercesión de los sacerdotes y la reverencia del lugar le permitirían obtener la piedad real, teniendo siempre presente la justicia (quod si ipse mali sui prius reminiscens ad ecclesiam fecerit confugium, intercessu sacerdotum et reuerentia loci regia in eis pietas reseruetur comitante iustitia).

Algún tiempo después, el rey Chindasvinto publicó una ley en el segundo año de su reinado (643/644) en la que de nuevo se recordaban los prófugos que desde los tiempos de Chintila buscaban amparo entre los enemigos del Reino (Lib. iudic., II, 1, 8 [p. 53-57]). El problema debía ser tan grave que el propio monarca reconocía que los godos se veían obligados a tomar las armas más veces por esta razón que por los ataques de las naciones vecinas (hac occasione potius quam expugnandorum hostium externorum arma sumere sepe conpellimur). De esta manera, Chindasvinto decretó, mediante una ley recogida en el Código de Recesvinto, que cualquier individuo que desde los tiempos de Chintila hasta el momento de la promulgación de la ley, así como desde ese instante en adelante, marchara con un pueblo enemigo, lo hubiera hecho o tuviera intención de hacerlo, de tal modo que actuase de forma criminal contra el pueblo y la patria de los godos $^{14}$, sería condenado a muerte, pena que también padecería cualquiera que se rebelase dentro del reino; y si tal vez el rey perdonaba la vida a uno condenado por esta causa - haciendo así gala de su piedad-, el reo sufriría la pérdida de la vista, a fin de que no contemplase la destrucción en la que se había deleitado y llevase siempre una vida amarga. En cualquier caso, sus bienes serían confiscados por el fisco ${ }^{15}$.

14 Como vemos, la ley tenía un carácter retroactivo, y fijaba en el inicio del reinado de Chintila el momento en que debía comenzar a castigarse a aquellos que habían acudido a alguna potencia extranjera con el fin de hacerse con el poder; remontarse más en el tiempo hubiera significado condenar a todos aquellos que todavía vivían y que se habían rebelado contra Sisenando. El hecho de poner el propio ascenso de Chindasvinto al trono como el punto en que la ley actuaba contra los que se hubieran rebelado dentro del reino tenía todavía una razón de ser más evidente: el propio Chindasvinto había alcanzado el poder después de sublevarse contra Tulga, tonsurarle y hacerlo de esta manera incapaz de reinar (Thompson $2007^{5}, 229$ ).

15 El Código de Ervigio recoge esta disposición, aunque modifica las penas al recordar que aunque el reo no fuera castigado con la muerte o la privación de la vista - puniciones que la ley había aplicado hasta ese momento-, el culpable sería decalvado, golpeado con cien azotes y condenado al exilio perpetuo junto con la confiscación de sus bienes, los cuales irían a parar al fisco. 
A partir de aquí, Edward A. Thompson ha deducido, acertadamente en nuestra opinión, que «a la vista del durísimo lenguaje con que los obispos condenaron continuamente la usurpación, no resulta descabellado pensar que hubiera estallado una o más rebeliones, apoyadas por un poder extranjero, tanto en la primavera de 636 como en el curso del año 637. Es todo lo que podemos adivinar» (Thompson $2007^{5}$, 219). Por desgracia, las fuentes resultan muy poco explícitas, y, aunque nos permiten conjeturar la existencia de las rebeliones sospechadas por Thompson (Thompson $2007^{5}, 218-219$ y 227-228), su ambigüedad es tal que nos impiden ir más allá y conocer los nombres de los rebeldes y las acciones concretas contra Chintila ${ }^{16}$.

La dura ley de Chindasvinto fue refrendada mediante un juramento prestado por los clérigos, los jueces y los palatinos. El Concilio VII de Toledo, del año 646, alude a dicho juramento, y recuerda que nadie que fuera acusado de tránsfuga y de pasar a la sociedad de otro pueblo a fin de actuar contra los godos y su rey sería reintegrado en sus bienes, excepto si la bondad del monarca consentía en ello, y en este caso tan solo podría recibir la vigésima parte de su patrimonio (Conc. Tol. VII, 1 [p. 342-343]; véase: Orlandis 1987, 152; García Moreno 1998², 162-163; Orlandis 2006², 108; Loring et alii 2007, 185; Thompson 20075, 229-231). En el mismo canon se invocaba el grave problema que para la nación goda suponían estas deserciones de usurpadores (tyranni) y tránsfugas (refugae): quis enim nesciat quanta sint hactenus per tyrannos et refugas transferendo se in externas partes illicite perpetrata et quam nefanda eorum superbia ingiter frequentata, quae et patriae diminutionem aferrent et exercitui Gotorum indesinentem laborem imponerent? (Conc. Tol. VII, 1 [p. 340]). Lo peor era que, según reconocían los obispos, entre estos individuos no solo había laicos, sino también clérigos traidores. Los asistentes al sínodo decidieron que todo eclesiástico, independientemente de su rango, que se expatriara a otro reino y desde allí pudiera hacer daño al pueblo de los godos y especialmente a su rey sería desposeído del grado de su honor y en su lugar habría otro individuo que se ocuparía del puesto que este había desempeñado; además, también sería excomulgado y solo si se arrepentía y cumplía la debida penitencia sería aceptado en la comunión al final de su vida. Si antes de que llegara ese momento, recibía la comunión de manos de cualquier sacerdote - aunque fuera por mandato del rey-, dicho sacerdote sería anatema (Conc. VII Tol., 1 [p. 341-342] $)^{17}$.

Algunos años después, Recesvinto, hijo de Chindasvinto, intentó dulcificar un poco la legislación de su padre referida a estos traidores. En el tomus presentado ante los asistentes al Concilio VIII de Toledo $(653)^{18}$, y tras evocar el juramento prestado por los palatinos y todo el pueblo, por el cual es-

16 Luis A. García Moreno también considera que bajo Chintila hubo «numerosos intentos abortados de conjuras y rebeliones nobiliarias» (García Moreno $\left.1998^{2}, 158\right)$. Un análisis del agitado reinado de este monarca en García Moreno 1998², 158-160.

17 Esta legislación debía cumplirse de una manera harto rigurosa, como observamos en la biografía de Fructuoso de Braga. En una ocasión, cuando todavía era obispo de Dumio, este deseaba dirigirse a Oriente en peregrinación, pero realizando su viaje en secreto y sin comunicarlo oficialmente, lo que en sí constituía una ilegalidad, pues no lo diferenciaba en nada de los clérigos que se expatriaban por motivos políticos. Poco antes de su partida, fue denunciado por uno de sus discípulos, lo que le supuso ser llevado a presencia del rey y encarcelado. Posteriormente, el prelado fue perdonado e incluso promovido al arzobispado de Braga (Vit.
Sanct. Fruct., 17-18 [p. 110-112]; véase: Thompson $2007^{5}$, 231). Según Manuel C. Díaz y Díaz, los recelos de Chindasvinto ante el intento de partida de Fructuoso se debían en buena parte a que este último pertenecía a la familia de Sisenando, rival de la nueva dinastía (Díaz y Díaz 1974, 113, n. 2; véase también García Moreno 2011, 529-530).

18 Precisamente, pocos meses antes de la celebración de este concilio se había producido una nueva rebelión en el Reino Visigodo. La conocemos gracias a la epístola que el obispo Tajón de Zaragoza envió a Quirico de Barcelona a modo de prefacio de sus Sententiae (Taio Caes., Ep. ad Quir., 2-4 [c. 727-730]). Por ella sabemos que el líder de la revuelta era un tal Froya, seguramente un noble, pero del que poco más se puede decir: Luis A. García Moreno considera que sería «muy posiblemente el duque de la Tarraconense» (García Moreno 1998², 
tos se comprometían a castigar de la manera más atroz e irrevocable a todo aquel que intrigase contra el rey y la nación goda — de tal manera que el culpable jamás mereciera el perdón ni la disminución de su pena-, el monarca consideraba que esta sentencia era demasiado grave y contraria a la piedad, por lo que solicitaba a los presentes que tratasen sobre esta cuestión, a fin de ver si era posible mitigar la pena (Conc. Tol. VIII, Tom. [p. 375-376]) ${ }^{19}$. En el segundo canon, los obispos admitían la dificultad de la petición del monarca: una sedición tumultuosa perpetrada por algunos tránsfugas y que había llevado la ruina a muchos pueblos obligó a pronunciar el mencionado juramento. Este se había hecho en nombre de Dios, por lo que no podía romperse sin cometer perjurio - las Escrituras prohibían tomar el nombre de Dios en vano- - Pero los obispos también reconocían la crueldad de las penas, y que la Biblia recomendaba la piedad. Y dado que la misericordia era preferible al perjurio, se decidió que los juramentos sobre la traición habrían de ser observados siempre que no implicasen amputación de miembros o sentencia de muerte (Conc. Tol. VIII, 2 [p. 386-412]). Esto suponía que el resto de penas se aplicarían igual: los expatriados no podrían regresar y los expropiados no podrían recuperar sus bienes (Orlandis 1987, 161-162; García Moreno 1998², 166; Orlandis 2006², 111; Loring et alii 2007, 187-188; Thompson 20075, 237-238) ${ }^{20}$.

Regresando a la decretal de Honorio I, y a modo de conclusión, consideramos que resulta muy probable que nos hallemos ante un precioso testimonio de lo que pudo haber sido una parte de la actividad de los refugae en tierras extranjeras. Aunque por desgracia la carta papal no se nos ha conservado $^{21}$, la respuesta que Braulio de Zaragoza redactó en nombre de los prelados hispanos nos

165); Roger Collins juzga que con probabilidad se trataría de un conde (Collins 2004, 84); Joaquín Martínez Pizarro y Pablo C. Díaz opinan que tal vez él mismo era un exiliado (Martínez Pizarro 2005, 26; Díaz et alii 2007, 426). El propio Tajón lo califica de homo pestifer atque insani capitis, y nos dice que asumió la tiranía - es decir, se proclamó ilegalmente rey-en contra del monarca legítimo Recesvinto. Para ello contó con la ayuda de los vascones, quienes bajaron de los Pirineos y provocaron muchos disturbios en el valle del Ebro. Tajón describe grandes matanzas, la captura de muchos cautivos y el expolio de un gran botín. Estas acciones generaron también un gran daño a la Iglesia: muchos altares sagrados fueron destruidos y numerosos clérigos fueron decapitados y dejados insepultos, convirtiéndose en pasto de perros y de aves de rapiña. La guerra llegó hasta Zaragoza, ciudad que fue sitiada por los insurgentes. Tajón recuerda que a causa de este peligro resultaba imposible abandonar la urbe, de tal manera que él mismo consagró sus noches a trabajar en las Sententiae. Finalmente, las tropas de Recesvinto llegaron a Zaragoza, derrotaron a los rebeldes y el propio Froya sufrió "la ignominia de una muerte atroz» (illi uero inferens atrocissimae mortis ignominiam). Estos ataques de los vascones también fueron recordados en la Chronica $\mathrm{Mu}$ zarabica anni 754 (Chron. Muzar. a. 754, 27 [p. 200]); véase López Pereira 2009, 201, n. 6. Respecto a la rebelión de Froya, véase: García Moreno 1974, 50, n. ${ }^{\circ}$ 62; Orlandis 1987, 158-159; Orlandis 1992, 138-139; Collins 2004, 84-85; Martínez Pizarro 2005, 25-26; Or- landis 2006², 109 y 409-410; Loring et alii 2007, 187; Thompson 20075, 237.

19 Es posible que tras este gesto de clemencia por parte de Recesvinto se hallase la influencia de Fructuoso de Braga, quien no mucho antes había remitido una misiva al monarca recomendándole que suavizase los castigos contra los culpables de traición (Fruct., Ep. ad Rec. [p. 688-689]; véase García Moreno 1998², 166).

20 Después del Concilio VIII de Toledo, no volvemos a encontrar nuevas referencias a los refugae en las fuentes visigodas. En palabras de Edward A. Thompson: «en nuestros documentos, estos émigrés hacen su primera aparición en las actas del II Concilio de Chintila, aunque es posible que Sisenando fuera calificado de refuga en 631. Se habla mucho de ellos en el reinado de Chindasvinto y en los primeros años de Recesvinto, aunque no se nos da ningún indicio sobre qué tipo de hombres eran, sobre su identidad y sobre el poder o poderes extranjeros cuya ayuda habían solicitado. Desaparecen de los documentos tan misteriosamente y repentinamente como habían aparecido» (Thompson 20075, 238-239).

21 Ángel Custodio Vega considera que la razón de que no conservemos la carta papal se debe a que los obispos hispanos no desearon guardarla, dado que se trataba de un documento injurioso para el episcopado hispano y tampoco dejaba en buen lugar al papa. «Ni para la memoria del Sumo Pontífice ni del Episcopado Español era conveniente su conservación» (Vega 1942, 97 , n. 1). 
revela que fueron unos falsiloqui los que se dirigieron al pontífice a fin de denunciar ante él una actitud frente a los enemigos de la fe que consideraban en exceso laxa. Honorio I señalaba directamente a los obispos como los responsables de tal relajación, pero resulta evidente que el reproche también alcanzaría al monarca godo, aunque fuera de un modo velado ${ }^{22}$. De ahí que, en su réplica, Braulio no solo insistiera en la probidad de los eclesiásticos, sino también en la rectitud del gobierno del rey Chintila. A partir de aquí, juzgamos verosímil la siguiente hipótesis: algunos de los rebeldes que se habían exiliado del Reino Visigodo en tiempos de Chintila, y que habían buscado refugio en los territorios vecinos — sin que nos resulte posible establecer en cuál ${ }^{23}$ —, se habrían dirigido al papa con la finalidad de formular la mencionada denuncia. Evidentemente, si por un lado deseaban lograr apoyos militares para su causa - regresar a la península ibérica y conquistar el trono de los godos-, por otro lado necesitaban justificarla, obteniendo incluso, si era posible, la sanción del papa para sus futuros actos ${ }^{24}$. Para ello resultaba imprescindible presentar ante el sucesor de Pedro una imagen negativa del monarca, algo que lo descalificara como gobernante tanto a él como a los obispos que le daban soporte. Y la política permisiva con los judíos era una opción tan buena como cualquier otra. La airada reacción de Honorio I —recordemos que llegó a calificar de "perros» a los obispos hispanos - nos prueba que esta estrategia de los refugae resultó fructífera en un primer momento. Sin embargo, la respuesta de Braulio, tan respetuosa como concisa y contundente, junto con el envío de las actas conciliares pertinentes, parece que zanjó este asunto, pues no contamos con nuevas referencias a él en las fuentes. Honorio I seguramente dio por buenas las explicaciones del obispo zaragozano y olvidó el tema ${ }^{25}$, con lo que los exiliados que lo habrían originado habrían visto así frustrada una gran parte de sus esperanzas.

\section{FuENTES}

Braul(io) Caes(araugustanus), Ep(istulae), ed. L. Riesco, Epistolario de San Braulio. Introducción, edición crítica y traducción, Sevilla: Publicaciones de la Universidad de Sevilla, 1975.

Chron(ica) Muzar(abica) a (nni) 754, ed. J. E. López Pereira, Continuatio Isidoriana Hispana. Crónica mozárabe de 754. Estudio, edición crítica y traducción [Fuentes y estudios de Historia leonesa, 127], León:

22 Curiosamente, Ángel Riesco supone que en la decretal de Honorio I se incluiría una alabanza del rey Chintila y de su política contra los judíos, lo que lleva a este autor a afirmar: "el excesivo celo y vigilancia de Honorio I (...) pudo inducirle erróneamente a elogiar y amparar la política antisemita del rey Chintila» (Riesco 1993, 594-595). Lo cierto es que no hay nada en la misiva de Braulio que nos permita inferir que en la carta papal se recogía el más mínimo elogio del monarca godo (intuimos que, de una manera implícita, se trataría más bien de lo contrario). Existe ciertamente en la epístola del obispo de Zaragoza un encomio de Chintila, pero dicho enaltecimiento se debe a la pluma de Braulio, no a la de Honorio I.

${ }^{23}$ Podemos especular con que tal vez sería Aquitania, el Reino Franco o incluso la propia Roma. Descartamos el Reino Lombardo, pues su rey durante es- tos años, Rotario (636-652), era arriano, y difícilmente un exiliado hubiera podido ganarse el favor papal realizando sus reivindicaciones desde un reino gobernado por un monarca hereje.

24 Recordemos que, según Conc. Tol. VII, 1 [p. 341], algunos de estos refugae eran clérigos de diverso grado (quisquis in ordine clericatus a maximo gradu usque ad minimum constitutus in alienae gentis regionem se quacumque occasione transduxerit) que, olvidando su juramento de fidelidad al rey, habían apoyado las pretensiones al trono de otro individuo (sed et quia plerosque clericos tantae leuitatis interdum prauitas eleuat ut, praetermissa sui ordinis grauitate ac polliciti sacramenti immemores, constante principe cui fidem seruare promiserant, in alterius erectione temeraria leuitate consentiant [p. 343-344]).

25 En este sentido, Ferreiro 2009, 94. 
Centro de Estudios e Investigación «San Isidoro» - Caja España de Inversiones - Archivo Histórico Diocesano, 2009.

Conc(ilium) Tol(etanum) III, ed. F. Rodríguez, La Colección Canónica Hispana, V, Madrid: Instituto Enrique Flórez, Consejo Superior de Investigaciones Científicas, 1992, 49-159.

Conc(ilium) Tol(etanum) IV, ed. F. Rodríguez, La Colección Canónica Hispana, V, Madrid: Instituto Enrique Flórez, Consejo Superior de Investigaciones Científicas, 161-274.

Conc(ilium) Tol(etanum) VI, ed. F. Rodríguez, La Colección Canónica Hispana, V, Madrid: Instituto Enrique Flórez, Consejo Superior de Investigaciones Científicas, 293-336.

Conc(ilium) Tol(etanum) VII, ed. F. Rodríguez, La Colección Canónica Hispana, V, Madrid: Instituto Enrique Flórez, Consejo Superior de Investigaciones Científicas, 338-364.

Conc(ilium) Tol(etanum) VIII, ed. F. Rodríguez, La Colección Canónica Hispana, V, Madrid: Instituto Enrique Flórez, Consejo Superior de Investigaciones Científicas, 365-485.

Fredeg(arius), Chron(ica), ed. B. Krusch, MGH srm, 2, Hannover: Societas Aperiendis Fontibus Rerum Germanicarum Medii Aeui, 1888, 18-168.

Fruct(uosus), Ep(istula) ad Rec(esuindum), ed. W. Gundlach, MGH epist., 3, Berlin: Societas Aperiendis Fontibus Rerum Germanicarum Medii Aeui, 1892, 688-689.

Greg(orius) Magn(us), Moral(ia) in Iob, ed. M. Adriaen, CCSL, 143-143B, Turnhout: Brepols Publishers, 1979-1985, 3 vols.

—, Reg(ula) past(oralis), ed. F. Rommel, SChr, 381-382, Paris: Éditions du Cerf, 1992, 2 vols.

Greg(orius) Tur(onensis), Hist(oriae), ed. B. Krusch, W. Levison, MGH srm, 1, 1, Hannover: Societas Aperiendis Fontibus Rerum Germanicarum Medii Aeui, 1951², 1-537.

Isid(orus) Hisp(alensis), Sent(entiae), ed. P. Cazier, CCSL, 111, Turnhout: Brepols, 1998.

Lib(er) iudic(iorum), ed. K. Zeumer, MGH leg., 1, 1, Hannover - Leipzig: Societas Aperiendis Fontibus Rerum Germanicarum Medii Aeui, 1902, 33-456.

Taio Caes(araugustanus), Ep(istula) ad Quir(icum), ed. M. Risco, PL, 80, Paris, 1850, 727-730.

Vit(a) Sanct(i) Fruct(uosi), ed. M. C. Díaz y Díaz, La Vida de San Fructuoso de Braga. Estudio y edición crítica, Braga: Diário do Minho, 1974.

\section{BibLIOGRAFÍA}

Aznar, S., 1986, San Braulio y su tiempo. El fulgor de una época, Zaragoza: Heraldo de Aragón.

Bonfit, R., 2012, "Continuity and Discontinuity (641-1204)», en: R. Bonfil et alii (eds.), Jews in Byzantium. Dialectics of Minority and Majority Cultures [Jerusalem Studies in Religion and Culture, 14], Leiden-Boston: Brill, 65-100.

Cabrera, J. A., 2014, «Dos episodios conflictivos entre el episcopado hispano y la sede apostólica de Roma durante el siglo VII», Studi Romani 62, 103-116.

Collins, R., 2004, Visigothic Spain, 409-711, Oxford: Blackwell Publishing.

Conte, P., 1971, Chiesa e primato nelle lettere dei papi del secolo VII, Milano: Editrice Vita e pensiero.

Dagron, G., \& V. Déroche, 2010, Juifs et chrétiens en Orient byzantin, Paris: Association des amis du Centre d'histoire et civilisation de Byzance.

Díaz, P. C., C. Martínez \& F. J. SAnZ, 2007, Hispania tardoantigua y visigoda [Colección Fundamentos, 181], Madrid: Istmo.

Díaz y Díaz, M. C., 1974, La Vida de San Fructuoso de Braga. Estudio y edición crítica, Braga: Diário do Minho.

Durliat, J., 1998, «L'épitaphe du pape Honorius», en: I. Ševčenko, I. Hutter (eds.), AETOS: Studies in Honour of Cyril Mango, Stuttgart-Leipzig: B. G. Teubner, 71-86.

Ferreiro, A., 2009, «St. Braulio of Zaragoza's Letter 21 to Pope Honorius I Regarding Lapsed Baptized Jews», SEJG 48, 75-95. 
—, 2010, «The Iberian Sueve-Visigoth Kingdoms in Gregory of Tours», en: L. M. Ferrer (ed.), Venti secoli di storiografia ecclesiastica: bilancio e prospettive. Atti del XII Convegno internazionale della Facoltà di Teologia "La storia della Chiesa nella storia» (Roma 13-14 marzo 2008), Roma: Edizioni Santa Croce, 279-291.

Fita, F., 1870-1871, «El Papa Honorio I y San Braulio de Zaragoza», La Ciudad de Dios 1, 4 (1870), 187204 y 260-278; 2, 5 (1871), 271-279, 358-365 y 447-458; 2, 6 (1871), 49-60, 101-107, 192-200, $252-$ 260, 336-346 y $403-429$.

-, 1881, Suplementos al Concilio Nacional Toledano VI, Madrid: Imprenta de D. Antonio Pérez Dubrull.

García Moreno, L. A., 1974, Prosopografía del reino visigodo de Toledo [Acta Salmanticensia. Filología y letras, 77], Salamanca: Universidad de Salamanca.

—, 1993, Los judios de la España antigua. Del primer encuentro al primer repudio, Madrid: Rialp.

—, 1998², Historia de España visigoda, Madrid: Cátedra.

—, 2011, «Relaciones internacionales del reino godo de Toledo en el siglo VII: de la faida gótica a la obsesión bizantina», en: Le relazioni internazionali nell'Alto Medioevo. LVIII Settimane di studio della Fondazione Centro Italiano di Studi sull'Alto Medioevo (Spoleto, 8-12 aprile 2010), Spoleto: Fondazione Centro Italiano di Studi sull'Alto Medioevo, 481-559.

González Salinero, R., 2000, Las conversiones forzosas de los judios en el reino visigodo [Serie Histórica, 2], Roma: Consejo superior de Investigaciones Científicas.

Jaffé, P., 1885, Regesta pontificum Romanorum ab condita ecclesia ad annum post Christum natum MCXCVIII, I, Leipzig: Veit et Comp.

Judic, B., 2013, «Grégoire le Grand et les Juifs, pratiques juridiques et enjeux théologiques», en: J. Tolan et alii (eds.), Jews in Early Christian Law: Byzantium and the Latin West, $6^{\text {th }}-11^{\text {th }}$ centuries [Religion and Law in Medieval Christian and Muslim Societies, 2], Turnhout: Brepols, 95-117.

KaegI, W. E., 2003, Heraclius, Emperor of Byzantium, Cambridge: Cambridge University Press.

Kendall, K. H., 2006, "Mute Dogs, Unable to Bark". Innocent III's Call to Combat Heresy», en: W. P. Müller, M. E. Sommar (eds.), Medieval Church Law and the Origins of the Western Legal Tradition. A tribute to Kenneth Pennington, Washington D.C.: The Catholic University of America Press, $170-178$.

LACARra, J. M., 1960, «La Iglesia visigoda en el siglo vil y sus relaciones con Roma», en: Le Chiese nei regni dell'Europa occidentale e i loro rapporti con Roma sino all'800. VII Settimane di studio del Centro Italiano di Studi sull'Alto Medioevo (7-13 aprile 1959), Spoleto: Centro Italiano di Studi sull'Alto Medioevo, 353-384.

López Pereira, J. E., 2009, Continuatio Isidoriana Hispana. Crónica mozárabe de 754. Estudio, edición crítica y traducción [Fuentes y estudios de Historia leonesa, 127], León: Centro de Estudios e Investigación «San Isidoro» - Caja España de Inversiones - Archivo Histórico Diocesano.

Loring, M. I., D. Pérez \& P. Fuentes, 2007, La Hispania tardorromana y visigoda, Madrid: Síntesis.

Lynch, C. H., \& P. Galindo, 1950, San Braulio, obispo de Zaragoza (631-651): su vida y sus obras, Madrid: Instituto Enrique Flórez, Consejo Superior de Investigaciones Científicas.

Magdalino, P., 2013, ««All Israel Will Be Saved»? The Forced Baptism of the Jews and Imperial Eschatology", en: J. Tolan et alii (eds.), Jews in Early Christian Law: Byzantium and the Latin West, $6^{\text {th }}-11^{\text {th }}$ centuries [Religion and Law in Medieval Christian and Muslim Societies, 2], Turnhout: Brepols, 231-242.

Martínez Pizarro, J., 2005, The Story of Wamba. Julian of Toledo's Historia Wambae regis, Washington D.C.: The Catholic University of America Press.

Mathisen, R. W., 2014, "Barbarian «Arian» Clergy, Church Organization and Church Practices», en: G. M. Berndt, R. Steinacher (eds.), Arianism: Roman Heresy and Barbarian Creed, Farnham-Burlington: Ashgate, 145-192.

McKenna, S., 1938, Paganism and Pagan Survivals in Spain up to the Fall of the Visigothic Kingdom, Washington D.C.: The Catholic University of America Press.

Miguel, R., 2010, «Ecos del Epistularium de Braulio de Zaragoza en la carta prefacio de Tajón de Zaragoza a Eugenio de Toledo (CPL 1267) en los Moralia in Job», Lemir 14, 289-300.

Orlandis, J., 1987, Historia de España. Época visigoda (409-711), Madrid, Gredos. 
—, 1992, Semblanzas visigodas, Madrid: Rialp.

—, 20062, Historia del reino visigodo español. Los acontecimientos, las instituciones, la sociedad, los protagonistas, Madrid: Rialp.

Riesco, A., 1993, «El problema judío en la mente de tres importantes personajes del siglo VII: un papa, un obispo español y un rey visigodo", ETF: Historia Antigua, Serie II 6, 585-604.

Rodamilans, F., 2014, «El primado romano en la Península Ibérica hasta el siglo X: un análisis historiográfico», ETF: Historia Medieval, Serie III 27, 421-461.

SaItTA, B., 1986, «I visigoti negli «Historiarum libri» di Gregorio di Tours», en: Los visigodos. Historia y civilización (Antigüedad y Cristianismo, 3), Murcia: Universidad de Murcia, 75-101.

—, 1995, L'antisemitismo nella Spagna visigotica [Studia Historica, 130], Roma: «L'Erma» di Bretschneider.

Sharf, A., 1995, Jews and Other Minorities in Byzantium, Jerusalem: Bar-Ilan University Press.

Thompson, E. A., 2007', Los godos en España, Madrid: Alianza Editorial (trad. J. Faci, The Goths in Spain, Oxford, 1969).

Van Dam, R., 1993, Saints and their Miracles in Late Antique Gaul, Princeton: Princeton University Press.

VeGA, A. C., 1942, El primado romano y la Iglesia española en los siete primeros siglos, El Escorial: Imprenta del Monasterio. 